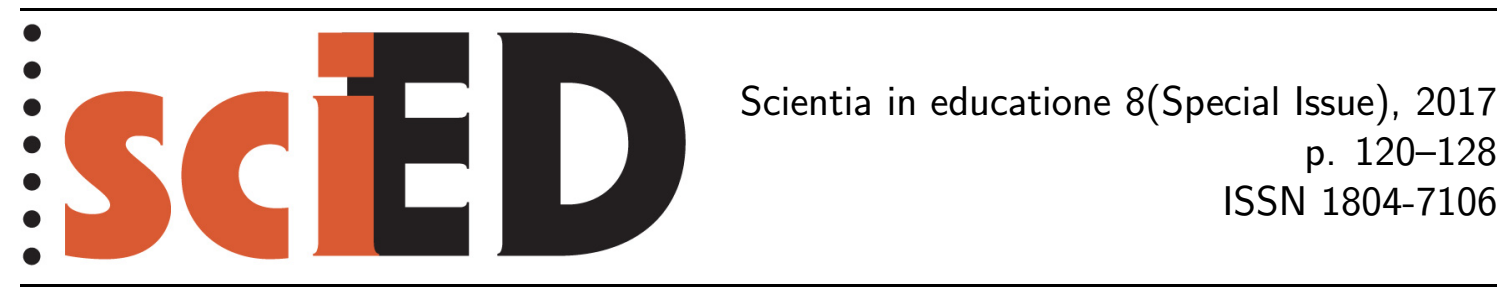

\title{
Science Interval Project: We Can Teach and Learn Physics During the Leisure
}

\author{
Francisco Adeil Gomes de Araújo, Meirivâni Meneses de Oliveira, \\ Eloneid Felipe Nobre
}

\begin{abstract}
The break between classes, still seen as an unproductive interval of time, in recent years, has been a cause of worry to the school community. The Science Interval Project aims to combine the science education with leisure time during the interval school, attracting the students for a time of learning and discovery. Specifically, the project aims to provoke and inspire the student to discover, build and give new meaning to knowledge and present to the school community the work developed in the classroom by the teacher and his students.
\end{abstract}

Key words: secondary education: upper, method and strategies of teaching, low cost experiments, teaching and learning physics. 


\section{INTRODUCTION}

Almost every physics teacher has to face the constant challenge of teaching a subject for which students generally have little interest. The lack of students' interest in studying and learn Sciences, in general. Physics, especially, is a great problem in the secondary schools, mainly in the public schools. The teachers are constantly fighting against this lack of student's interest, lack of structure that do not provides opportunities appropriate laboratory classes and currently some Brazilian teachers have face another difficulty in the exercise of their profession: the violence in schools. The enhance of violence in the school environment has been a source of concern for the whole school community: of the 456 public schools in the city of Fortaleza, capital of Ceará, in northeastern Brazil, 35 are in hazardous areas.

With the intention to collaborate to improve this state of affairs, we decided to develop and implement The Science Interval Project at a public school in one of the poorest neighborhoods of the city of Fortaleza. The project is being conducted in a Primary/Secondary School, located in Bom Jardim, neighborhood in Fortaleza. The region is known for high rates of violence and the school has experienced the loss of students because of fights between gangs and use of drugs. This violence came to the school environment, for example, by aggressive jokes and fights during the interval of the classes. Searching a solution to this situation, we developed this project in school seeking to involve the students in activities that awake their interest and can be performed in a cooperative way. On the last Friday or Wednesday of each month, the projects and experiments developed by teachers and students in the classroom and in the science laboratory are presented in the schoolyard. The presentation is made by the students who were chosen by their teachers, or those who have expressed an interest in participating. The use of low cost experiments is prioritized, because the school does not have a suitable science laboratory.

\section{OBJECTIVES}

The main objective of this project is to combine the science education with leisure during the time of the interval school, attracting the students for a time of learning and new discoveries in the 20 minutes of interval between classes, without forgetting its purpose that the students can relax and have fun, before continuing their scheduled classes.

Specifically, we also intend: to provoke and inspire the student discovers, builds and gives new meaning to knowledge; to submit to the school community the work developed in the classroom by the teacher and his students; to create a culture of practical classes in school, beyond the traditional lectures using only crayon and blackboard; to awake the curiosity and taste for science among the students.

\section{Methodology}

The project began in May 2012, in a public school for basic education, located in a poor neighborhood in Fortaleza, capital of Ceará, in Northeast Brazil. Thinking of using not only the classrooms but also the gap of time between the classes, arises the project that aims to lead the science in the Interval of the classes, moments otherwise often occupied by fights, and even dangerous accidents.

The teacher is the responsible for development of ideas and practical activities in the classroom. The experiments are developed by the students, with helping of 
teacher, about the contents studied. To construct the experiments, the students are tasked to collect, themselves, the materials, and the use of low cost experiments is prioritized.

Once a month, all experiments are presented to school. The students are in charge of presenting the experiments in the schoolyard during the interval between classes. They have the support of their teacher and of the science lab coordinator. The presentation of the experiments in the schoolyard, is made by the students who were chosen by teachers, or by those students who have expressed an interest in participating.

When an experiment cannot be repeated during the interval, such as the dissection of a bull's eye to understand the optics of human eye, photos of experiment are available on the blog of project (http://intervalociencia.blogspot.com.br/).

On the day of the presentations, the students are in charge for presenting, explaining the experiments and guide the other students who visit the tables of experiments and to return to their rooms when the interval ends. This occurs both in the morning and in the afternoon. They are also responsible for the organization of experiments and materials in the yard. The teacher only accompanies the process, in order to help them, if necessary.

The use of low cost experiments is prioritized, because the school does not have a suitable science laboratory, but some materials are acquired in the science laboratory of the school.

The activities began on May 2012, during the night class, with a lecture on Astronomy, delivered by members of the Astronomy Club of Fortaleza, followed by observation by students of the Moon and Saturn through telescopes.

The project was continued with presentations of experiments on reflection and refraction of light, and exposure of photos made with dark chambers built by students in 9th grade. This material was used by the whole school community, in the morning and afternoon.

The students presented various experiments with balloons, to demonstrate many kinds of contents, such as atmospheric pressure, heat transfer, circular motion and friction.

On July the project was stopped because of school holidays. The activities returned in August, but we had little time to develop new works since the attention of teachers and students were directed to the bimonthly evaluations.

The project began again on September. The teacher, in his classrooms of geometrical optics, developed, with his students, a photography project, aiming at building a machine called Pinhole Camera. The students built their own cameras using matchboxes, hair clips, among other materials. Then they chose a theme to photograph and sent to reveal. The photographs were exhibited at the school throughout the month.

During the month of September in addition to Physics, the project also included the participation of other experiments in the areas of Chemistry and Biology. The students extracted the DNA from some fruits, they performed analyzes of urine and also presented experiments on surface tension, density, condensation and sublimation. Even a student in the 6th grade of elementary school showed a robot he built using toothbrushes, and 9th grade students explained the decomposition and interference colors through huge soap bubbles.

With the development of the project, in addition to experiments on the subjects developed in the classroom, some students also presented experiments they searched at the internet, developed with the help of the coordinator of the science lab. The 
students presented experiments on phosphorescence and fluorescence, optical illusion, 3D technology, density of liquids. They built a periscope and some students built batteries using lemons and copper coins. As an activity linked to Biology, the students calculated the body mass index of their classmates.

During the month of November, the project was not presented at the school because the class teacher have been absent to attend the Meeting of the Physicists of the North and Northeast, a regional conference that annually gathers the community of physicists, researchers, students and teachers from the North and Northeast of Brazil.

During December, the Doppler effect was been studied, both for sound and light. Students used computer simulations and simple experiments to explain how astronomers discovered the expansion of the universe. In addition, was organized a competition of rockets, built by the students using plastic bottles. In the construction of rockets were addressed the three laws of Newton.

\section{AnAlyses AND Results}

The experiments were performed by approximately 80 students, with the guidance of the class teacher. Among these 80 students, 16 were selected to be monitors, which were in charge of the presentation of the experiments. The total number of students participating in the project's first phase was 204, including the students who performed the experiments, the monitors and the other students of the school who participated by attending the presentations and visiting the stands with the experiments, only attending the exhibitions.

The project also included the participation of teachers from several areas: three of Physics, two of Chemistry, two of Biology, three of Mathematics and still, one of Geography, which emphasizes its multidisciplinary perspective.

We conducted a survey with the 204 students to verify if the objectives of the project were being met. The results are shown below.

First of all, we wanted to know the point of views of students on the new method of learning. Their responses are showed on the Figure 1.

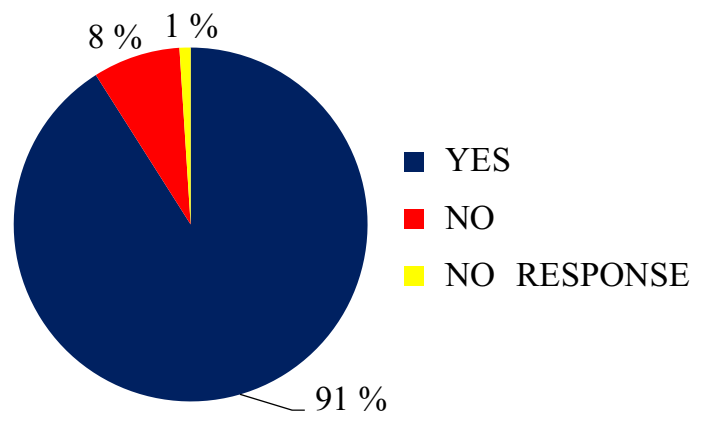

Figure 1: During the Science Interval you think you can learn science in a fun way?

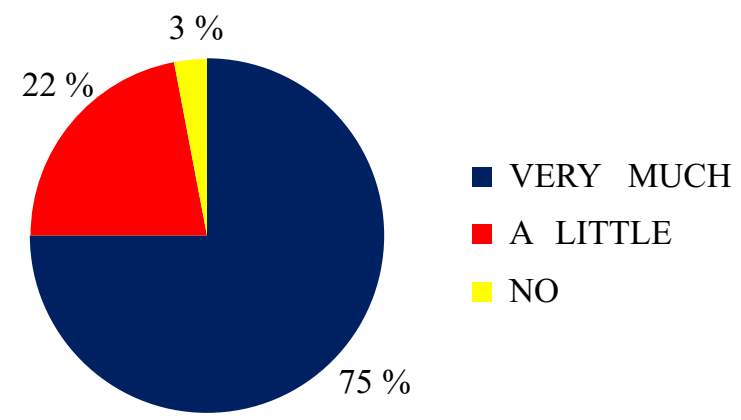

Figure 2: Do you participate in the moments of the Science Interval, visiting the tables and performing the experiments?

186 students, about $91 \%$; said Yes. 16 students, about $8 \%$; said No, and 2 students about $1 \%$, Did not answer.

With respect to the participation of students, we obtained the following results, showed on the Figure 2. 
154 students, about $75 \%$, have participated a lot of the presentations of the experiments. 44 students, about $22 \%$, participated a little, and only 6 students, about $3 \%$ did not participated.

Finally, when we asked if they thought that the project has contributed to an improvement in their performance in Physics classes, we obtained the following group of responses:

154 students, about $75 \%$, said Very much. 44 students, about $22 \%$, said they learned somewhat. Only 6 students, about $6 \%$ thought the project did not contribute to their learning.

The schedules of classes in the Brazilian schools are divided in periods: morning, afternoon and night. This information, related with the last question, were given mainly by the students of morning shift, composed by eleven groups. From these, two groups are formed by high school students and one of 9th grade of elementary school.

Only the high school students and those from the 9th grade participate regularly in the project, since these are the students who have Physics Chemistry and Biology in their school curriculum. This became more evident when analyzing the students' responses for the third question. When asked if the project was contributing to an improvement in their performance in science classes, where $75 \%$ of students responded very much, $22 \%$ said somewhat and $3 \%$ said it had contributed nothing.

We also monitor the student's results in the assessments of Sciences and Physics exams throughout the year 2012, when the project was implemented, compared to the results obtained in 2011, before the implementation of the Project.

The results are showed on the figures below.

To the students of the 9 th grade, which were evaluated in the contents of Sciences: Physics, Chemistry and Biology, we see the following results:

The graphics in yellow refer to the results of 2011 and green, the year 2012, when the project has been applied.

The results of assessments for the students in the high school level are showed in the graphs bellow. This group was composed by 27 students. The graphs show the results obtained in the assessments of Physics.

Natural Sciences

$100 \%$

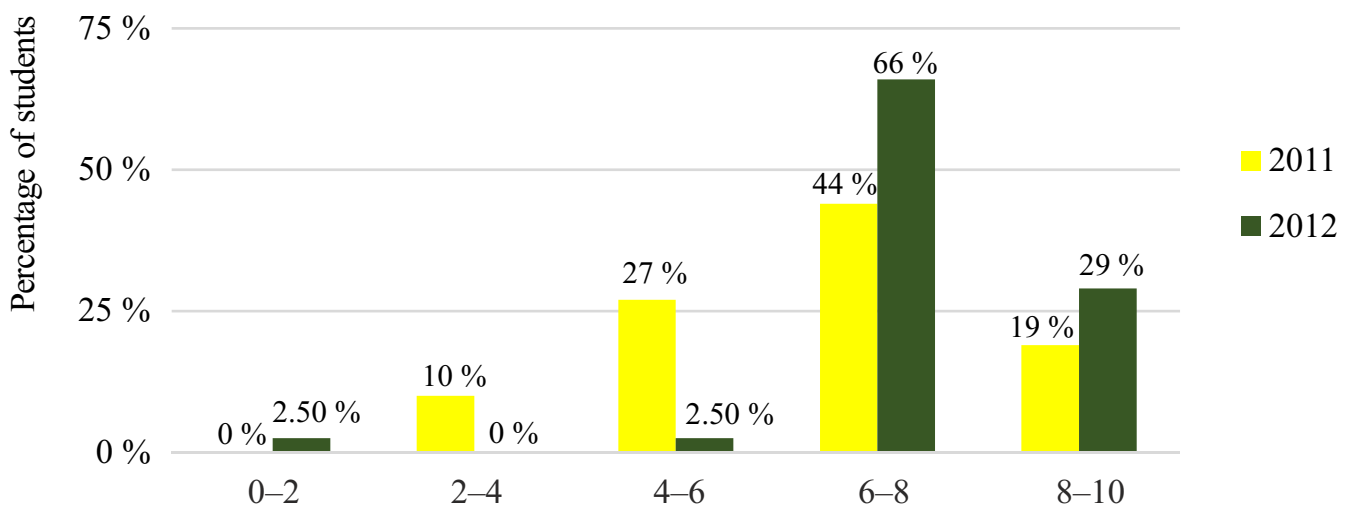

Figure 3: Results of bimonthly assessments of Sciences (March and April) 
$100 \%$

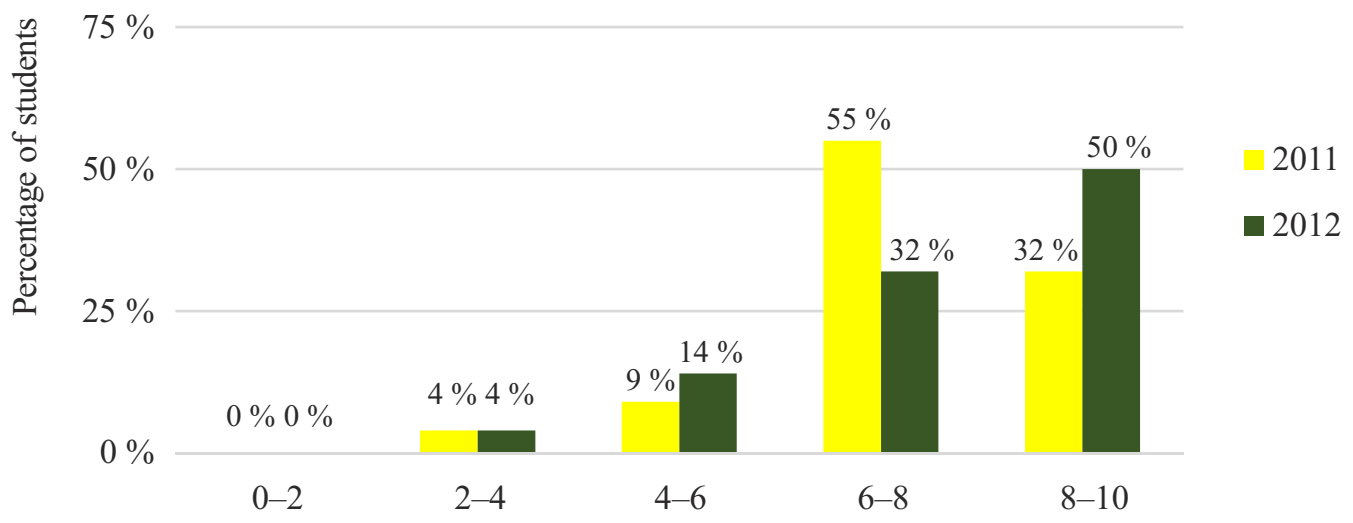

Figure 4: Results of bimonthly assessments of Sciences (May and June)

Natural Sciences

$100 \%$

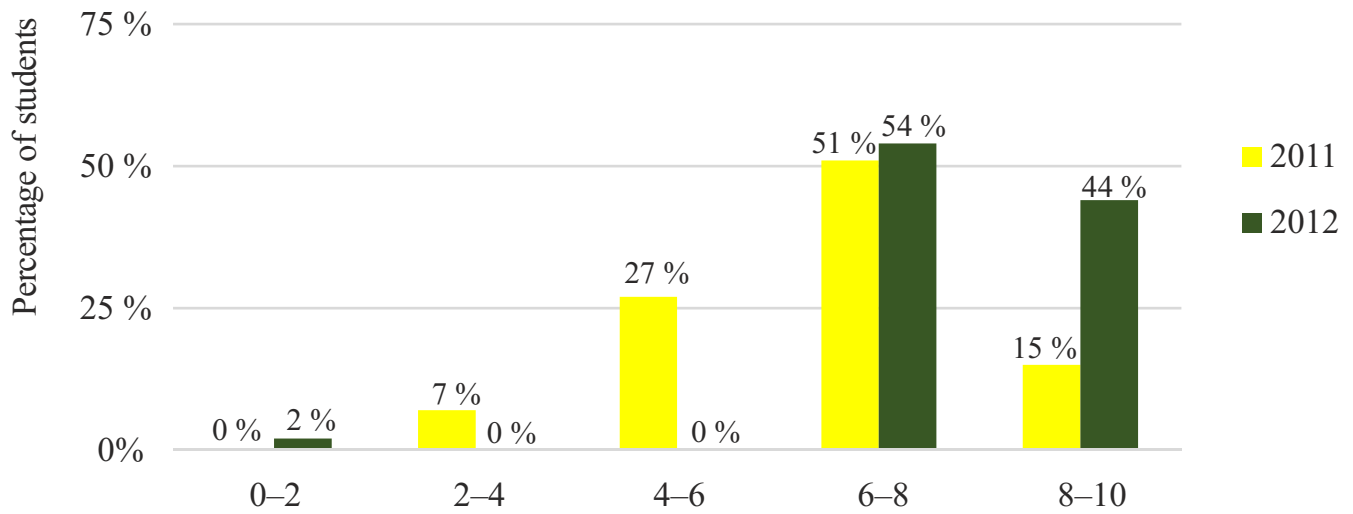

Figure 5: Results of bimonthly assessments of Sciences (August and September)

Natural Sciences

$100 \%$

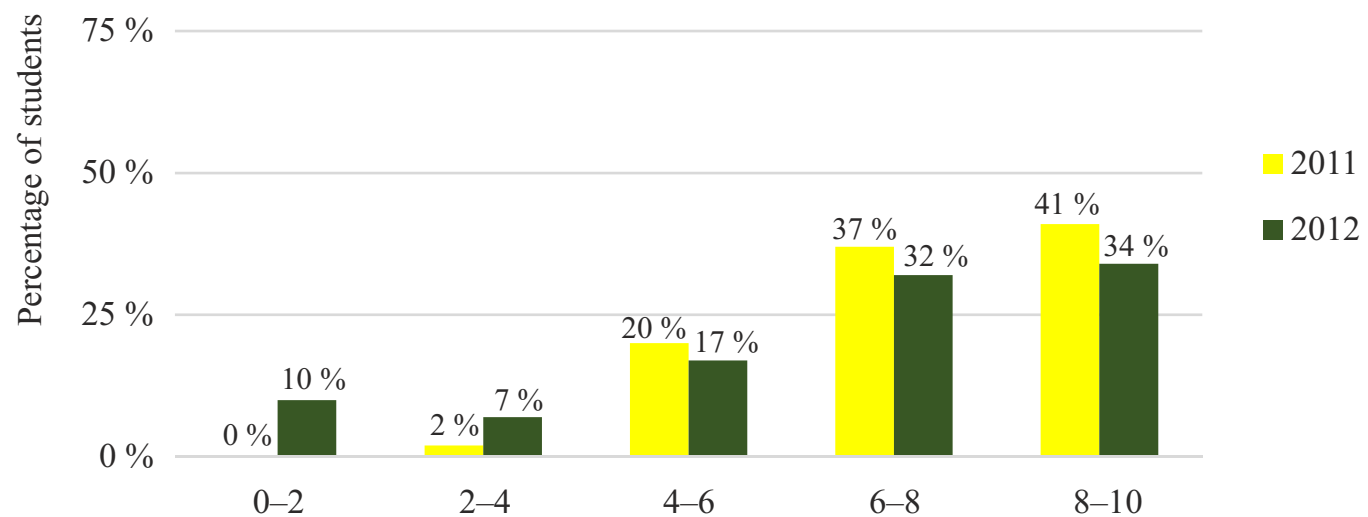

Figure 6: Results of bimonthly assessments of Sciences (October and November) 
$100 \%$

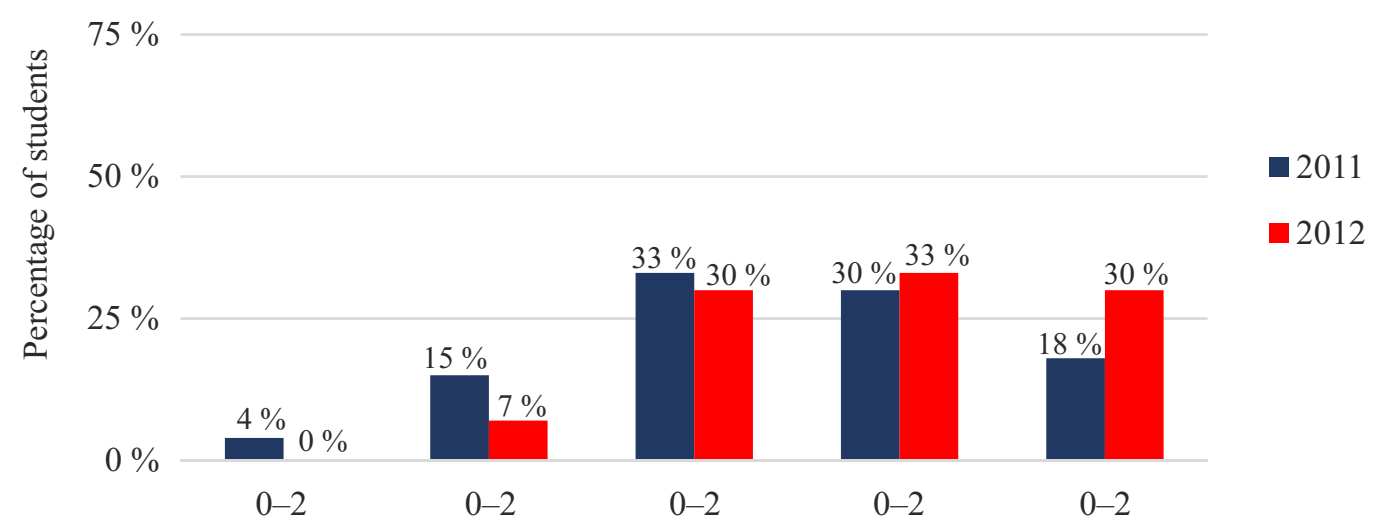

Figure 7: Results of bimonthly assessments of Physics (March and April)

Physics

$100 \%$

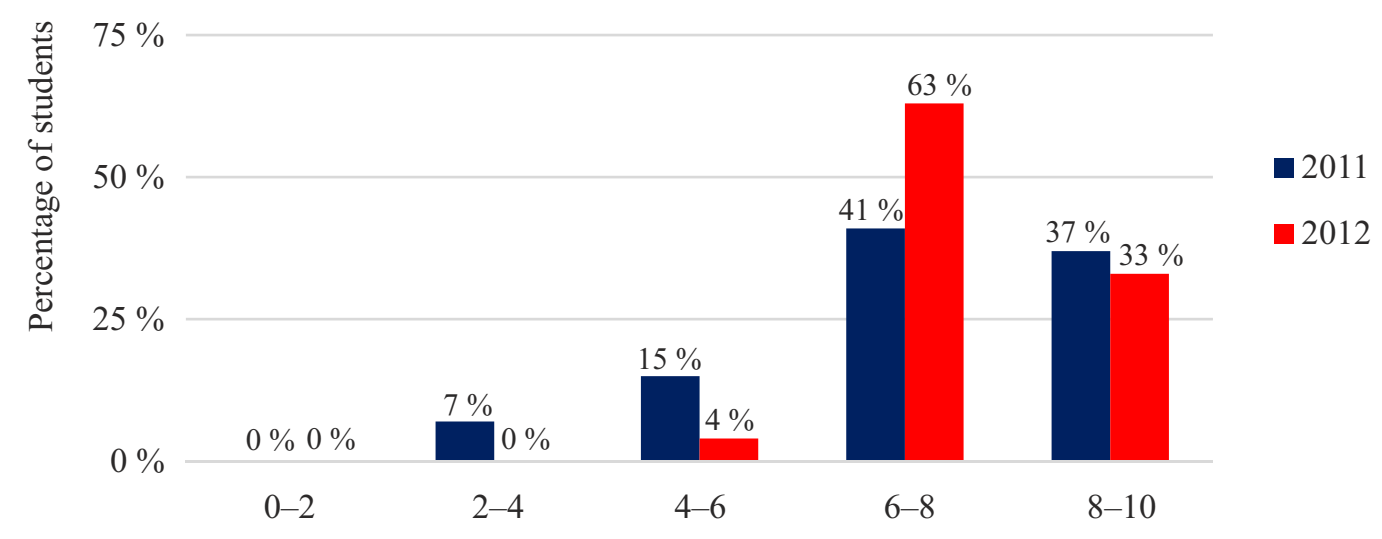

Figure 8: Results of bimonthly assessments of Physics (May and June)

Physics

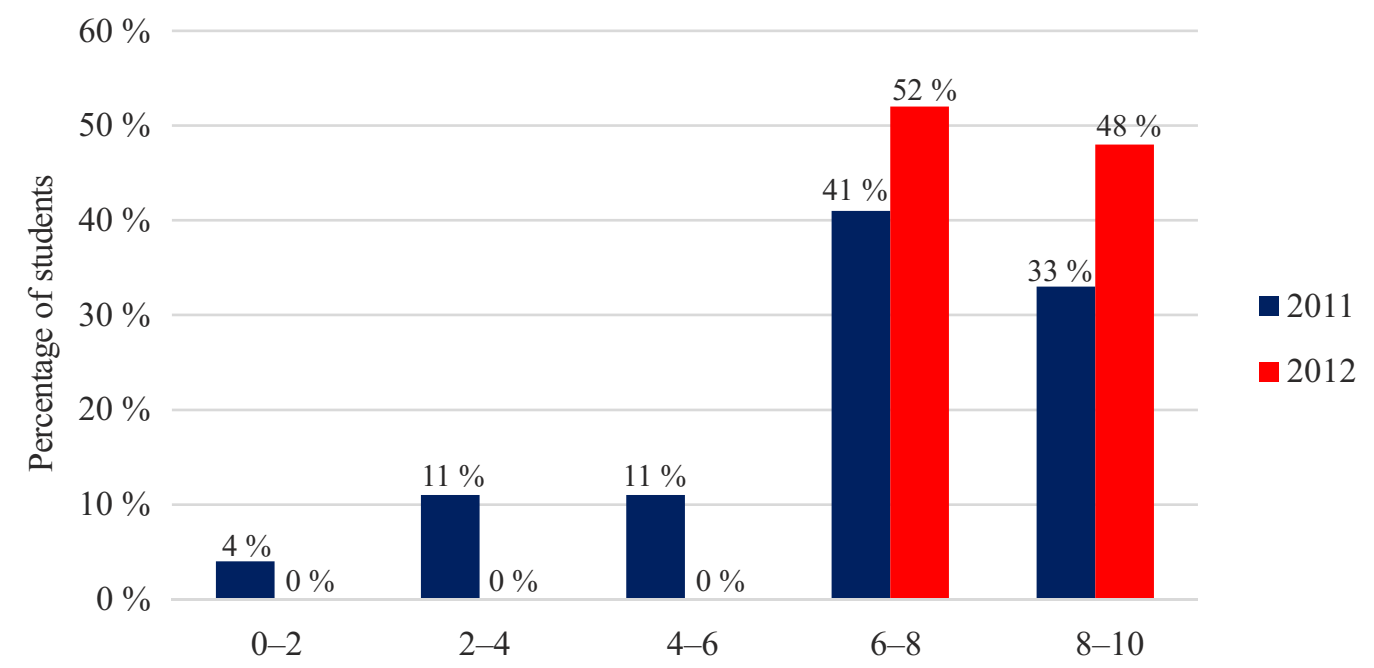

Figure 9: Results of bimonthly assessments of Physics (August and September) 
$100 \%$

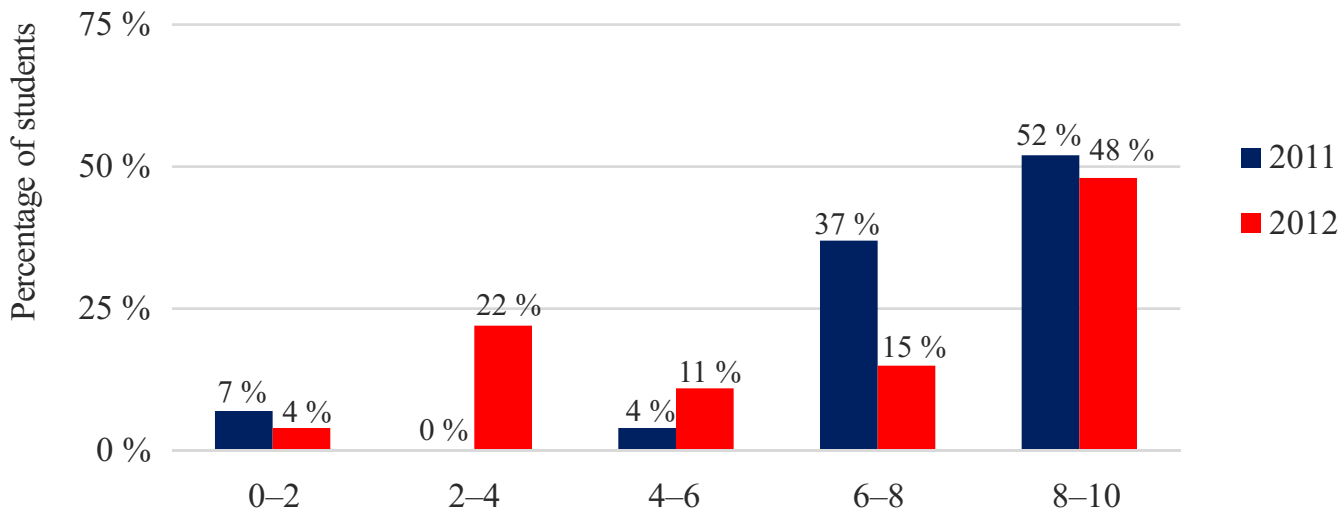

Figure 10: Results of bimonthly assessments of Physics (October and November)

The graphs show that, in general, the results obtained by the students in the assessments are better than that before the Science Interval Project was applied. The students were more involved and interested. Even the results of the fourth bimonthly assessments, which show in 2012 grades less than that of 2011, can be explained. In this period, we organized a competition with all the Physics contents, when the students had the opportunity to show the experiments related with the contents they learned during the year. In this latest assessments the tests were more extensive, covering the contents of the whole year and not just those seen in bimonthly periods.

We hope to get more data to analyze how the project has contributed to a more meaningful learning for the student.

\section{FINAL REMARKS}

The Science Interval Project is still a pilot project, and we intend to use the time of interval between the classes as another learning moment, but the results obtained until now suggest that the project is reaching its objectives.

Recent studies show that the method in which students perform the experiments by themselves and also themselves present them to their colleagues, results in a more meaningful learning, accumulating experiences that reach $90 \%$ of apprehension of the contents. Therefore, it is important to orientate the students to be more active in the process of teaching and learning.

The use of low cost experiments, because the school does not have an appropriate science lab, the act of teaching what they have learned, to present a project or experiment, leads the students in a remarkable improvement in their behavior, attitudes and self-esteem, and consequently in their learning.

The project has been changing the school routine. The whole school community is committed towards continuing the project, making it a routine. Teachers, students, all school community begin to understand that so important than only improving school performance, with good grades, is to make the student be able to construct their own knowledge and also changing his attitude in the society. We cannot forget of the contribution for the experimental classes. The project surely 
contributes to enhance the experimental classes, because the schools, in general, don't have an appropriate science lab.

Initially there was only one school and its 204 students involved in the project. Some dsses 204 students, were active, performing the experiments and acting as presenters of the experiments for the school community. Others only attended the exhibition. Nowadays the project is been presented to several schools and we have more than 400 students envolved.

Besides being taken to secondary schools, currently the project was adapted to be presented as workshops low cost experiments, as a complementary activity to the students of Physics of Federal University of Ceará, focused to teacher education.

\section{REFERENCES}

Moreira, M. A. \& Masini, S. F.E. (2001). Meaningful learning: The theory of David Ausubel. São Paulo: Centauro.

Neuenfeld, D. J. (2003). School break: What happens far from the teachers' eyes? Maringaá, 14(1), 37-45. Available at http://periodicos.uem.br/ojs/index.php/RevEducFis/article/viewFile/3479/2512

Teixeira, M. S. A. \& Vital, M. L.S. (2003). Experimental activities in physics teaching: Different approaches, different purposes. Brazilian Journal of Physics Teaching, 25(2).

Francisco AdeIl Gomes de AraúJo

Secretaria of Education of the State of Ceará

Federal University of Ceará

Meirivâni Meneses de Oliveira

Secretaria of Education of the State of Ceará

Eloneid Felipe Nobre

Federal University of Ceará 